\title{
Folding Large Antenna Tape Spring
}

\author{
Ö. Soykasap* \\ Afyon Kocatepe University, 03200 Afyonkarahisar, Turkey \\ S. Pellegrino \\ California Institute of Technology, Pasadena, California 91125 \\ and \\ P. Howard $\stackrel{ \pm}{ \pm}$ and M. Notter $\underline{\S}$ \\ EADS Astrium, Portsmouth, England PO3 5PU, United Kingdom
}

DOI: $10.2514 / 1.28421$

\begin{abstract}
This paper presents a novel concept for a low-mass, $50-\mathrm{m}^{2}$-deployable, $\mathrm{P}$-band dual polarization antenna that can measure terrestrial biomass levels from a spacecraft in a low Earth orbit. A monolithic array of feed and radiating patches is bonded to a transversally curved structure consisting of two Kevlar sheets. The first sheet supports the array and the other sheet supports a ground plane. The two sheets are connected by a compliant Kevlar core that allows the whole structure to be folded elastically and to spring back to its original, undamaged shape. Test pieces have been made to demonstrate both the radio frequency and mechanical aspects of the design, particularly the radio frequency performance before and after folding the structure. It is concluded that the proposed design concept has high potential for large, low-frequency antennas for low-cost missions.
\end{abstract}

\section{Introduction}

O $\mathrm{NE}$ of the biggest challenges of the 21 st century is that of maintaining the environmental balance of the planet. A key concern for environmental scientists is the balance between $\mathrm{CO}_{2}$ emissions and the capability of terrestrial vegetation to extract $\mathrm{CO}_{2}$ from the atmosphere. Measuring or estimating emissions is only half of the equation; we also need to have an accurate measure of the global biomass level, a major element of which is associated with tropical rain forests and boreal forests [1,2].

To achieve global monitoring of the planet, scientists have looked to satellite instruments to provide the appropriate data on a recurring basis. Existing optical or radar instruments can provide accurate measurements of the area of vegetation on the planet but none can penetrate the forest canopy to determine the actual density of the biomass [3,4]. The average boreal forest density is estimated to be 50 tons/ha, with maximum densities of 120 tons/ha. Existing space-based Synthetic Aperture Radar (SAR) systems, such as ASAR, ERS-2, and Radarsat-1, operate at too high a frequency (C band) and literally bounce off the canopy of these forests. Figure 1 shows that only with radars operating at or below $\mathrm{P}$ band can adequate penetration of these forests be achieved, thus allowing the provision of an accurate classification of the world's biomass. Note that, once the reflected signal level flattens out, there is no signal differentiation between biomass densities; hence, a saturation point (denoted by a star in the figure) is reached for that frequency.

The difficulty facing the SAR system designer is that existing instruments at $\mathrm{C}$ band $(5.3 \mathrm{GHz})$ are already over $10 \mathrm{~m}^{2}$, and to

Presented as Paper 1601 at the 47th AIAA/ASME/ASCE/AHS/ASC Structures, Structural Dynamics, and Materials Conference, Newport, RI, 14 May 2006; received 18 October 2006; revision received 4 November 2007; accepted for publication 8 November 2007. Copyright () 2007 by O. Soykasap, S. Pellegrino, P. Howard, and M. Notter. Published by the American Institute of Aeronautics and Astronautics, Inc., with permission. Copies of this paper may be made for personal or internal use, on condition that the copier pay the $\$ 10.00$ per-copy fee to the Copyright Clearance Center, Inc., 222 Rosewood Drive, Danvers, MA 01923; include the code 0022-4650/ $08 \$ 10.00$ in correspondence with the CCC.

*Associate Professor, Department of Mechanics, Ahmet Necdet Sezer Kampusu, Gazligol Yolu. Member AIAA.

${ }^{\dagger}$ Professor of Aeronautics and Civil Engineering, Graduate Aeronautical Laboratories, 1200 East California Boulevard, Mail Code 301-46. Fellow AIAA.

Principal Engineer, Mechanical Systems.

§Principal Engineer, RF, Anchorage Road maintain the same SAR performance the antenna area needs to increase linearly as the frequency decreases. Thus, at $\mathrm{P}$ band $(0.435 \mathrm{GHz})$, an antenna of $100 \mathrm{~m}^{2}$ is required to be launched and deployed in space. It is this packaging and structural problem and its unique solution that are the subjects of this paper.

\section{Antenna Requirements and Proposed Approach}

The science requirements and the resulting radio frequency (RF) design and analysis indicated that a $50-\mathrm{m}^{2}$ antenna at $\mathrm{P}$ band in a low Earth orbit (LEO) of approximately $630 \mathrm{~km}$ could provide the data needed to measure terrestrial biomass levels. This antenna would only be able to electronically scan between 20 and 30 deg off Nadir, instead of the usual 20-40 deg achievable with a $100 \mathrm{~m}^{2}$ antenna. However, this only affects the time taken to achieve global access by a few days (from 11 to 20 days) and not the quality of the data and, hence, was deemed acceptable. The antenna requirements affecting the mechanical design are as follows: 1) P-band antenna operating at $0.435 \mathrm{GHz}$; 2) quad polar operation, transmitting and receiving on both $\mathrm{H}$ and $\mathrm{V}$ polarizations and, hence, requiring two independent feed systems; 3) area of $50 \mathrm{~m}^{2}$ with a height of $2.82 \mathrm{~m}$ and a length of $17.29 \mathrm{~m}$; 4) deployed frequency of at least $0.5 \mathrm{~Hz}$, but ideally around $1 \mathrm{~Hz}$; 5) deployed antenna planarity better than $40 \mathrm{~mm}$; 6) stowed packaging to allow launch on a low-cost launch vehicle (Rockot, Vega, or Soyuz); and 7) low-mass design, to be compatible with the launch vehicles and, hence, a mass target of less than $1 \mathrm{~kg} / \mathrm{m}^{2}$.

RF design options already in use for higher-frequency SAR antennas include slotted waveguides (ERS-1 and 2 and Radarsat-1) and active phased arrays (ASAR and Radarsat-2). A tradeoff looked at the packaging (stowing and deploying) of these types of RF solutions to see what was viable and realistic for low-frequency SAR applications. The slotted waveguide solutions were ruled out due to the size of the P-band waveguide even though collapsible options were reviewed (see Fig. 2). Phased array antenna designs have relied on splitting the antenna length into separate panels that are then folded onto each other to produce a smaller panel stack, though adding deployment complications, mass, and cost (see Fig. $\underline{3}$ ).

The design solution with the highest score from the tradeoff exercise was a monolithic array with 5 rows of 28 radiating elements per row (see Fig. 4), based on a folding large antenna tape spring (FLATS) structure. It is this FLATS technology that is presented in this paper. The design solution is shown stowed and deployed on a satellite in Fig. $\underline{5}$. 


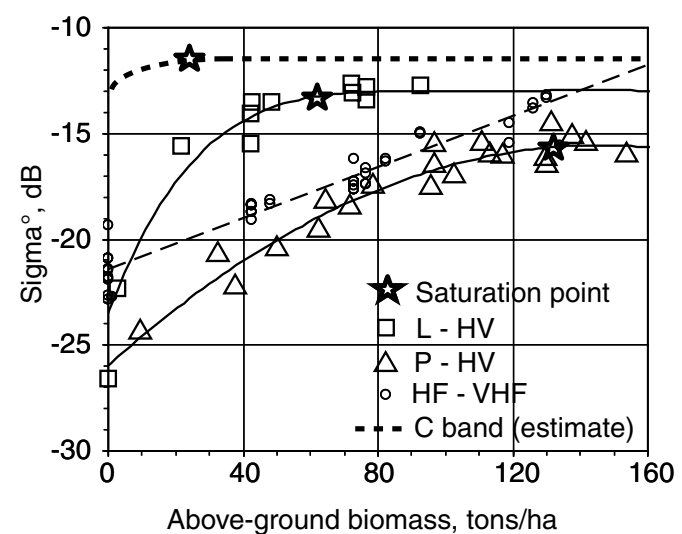

Fig. 1 Strength of signal reflected off vegetation of different density.

This paper summarizes the mechanical design of the full $50-\mathrm{m}^{2} \mathrm{P}-$ band antenna as well as the design, manufacturing, and testing of a test piece.

\section{Mechanical Design}

A. Monolithic Antenna Based on FLATS Concept

The basic concept, shown in Fig. $\underline{6}$, is a transversally curved sandwich plate structure forming a giant tape spring.
Tape springs are well known in the field of deployable structures. They were first studied by Wuest [5], who obtained an analytical expression for the moment-curvature relationship that allowed for changes in the transverse curvature. Their exploitation for deployable structures applications began with Rimrott's work, in the 1960s. Rimrott [6] was the first to show analytically that the longitudinal radius of an elastic fold in an isotropic tape spring is equal to the original, transverse radius of the shell [7]. Rimrott also determined the thickness limit for isotropic shells of different materials that are just on the point of yielding when they are folded. A detailed investigation of the edge deformation near a fold was carried out by Seffen and Pellegrino [8].

Recently, shells made of carbon-fiber reinforced plastic have been considered [9] ], leading to self-latching tubular hinges made of glass fiber or carbon fiber. These hinges are made by machining either two or three slots parallel to the axis of the cylinder [10,11].

The particular feature of tape springs that is exploited in all of these designs is that the curved cross section of a tape spring provides a significant increase in stiffness compared with a flat plate, yet once the transverse curvature has been removed, the stiffness reduces to that of the flat plate and, hence, the tape spring can be easily folded.

A single sheet tape spring with dimensions of 2.82 by $8.64 \mathrm{~m}$ would never be stiff enough; however, the RF design requires two sheets $20 \mathrm{~mm}$ apart, the ground plane being the second sheet. By joining together the two sheets with a core structure, an efficient structural design is obtained. However, because a standard sandwich core, such as a hexagonal honeycomb, would lead to a structure that
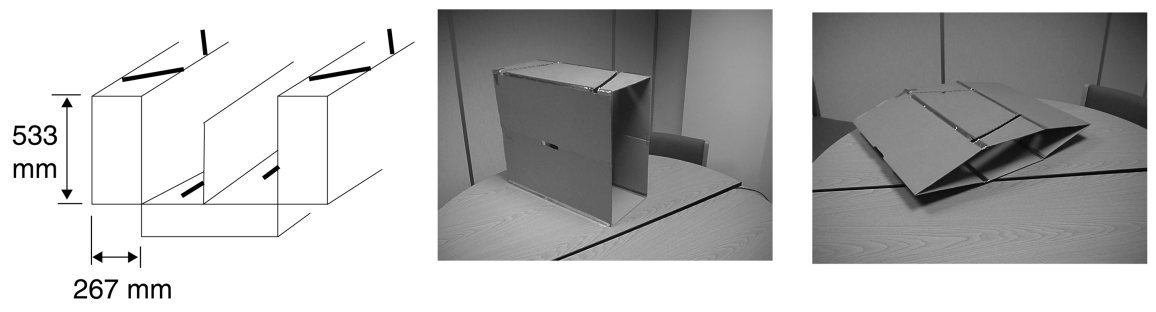

Fig. 2 Collapsible P-band waveguide solution.

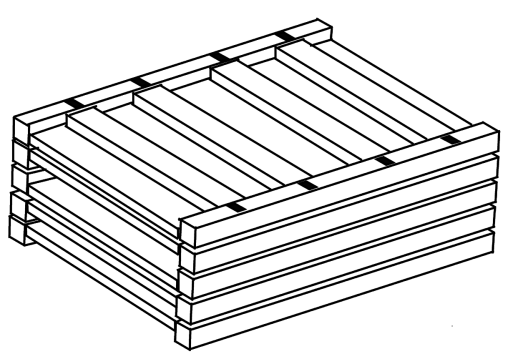

a)

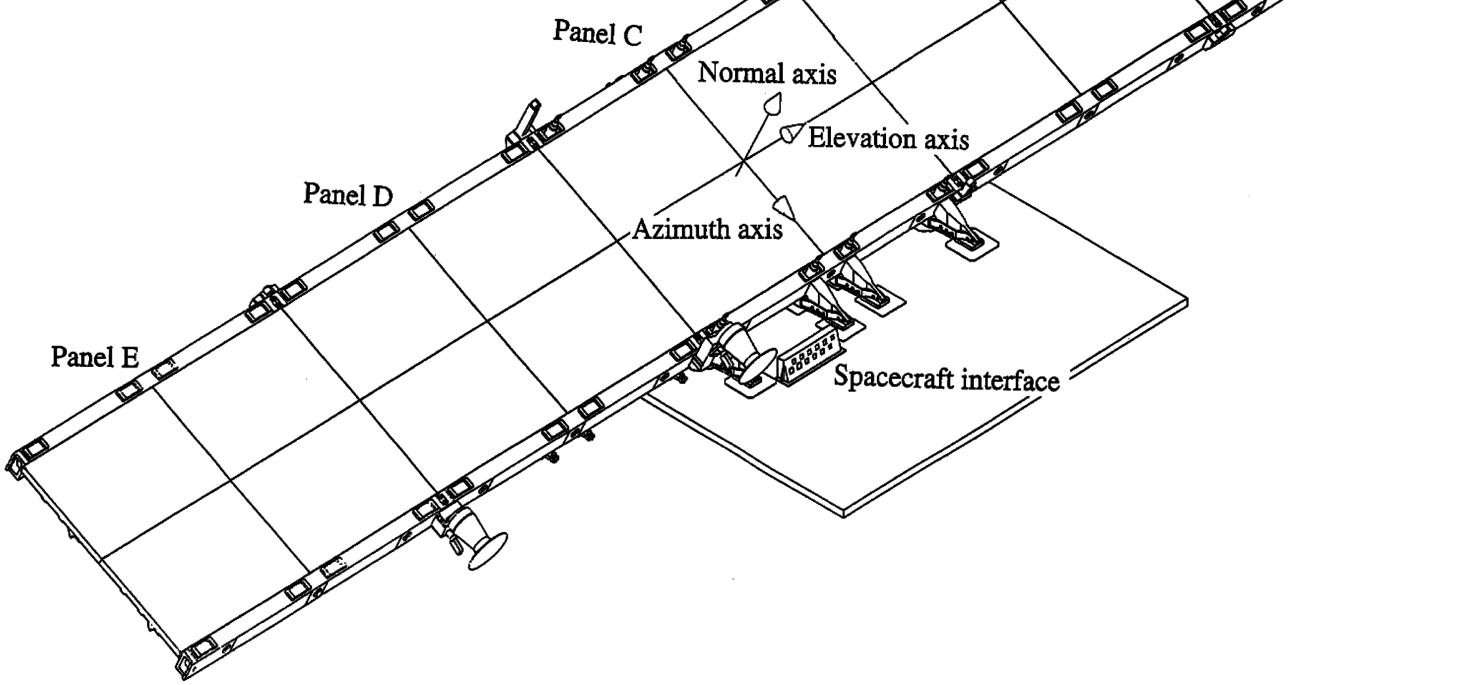

b)

Fig. 3 Active array antenna (ASAR): a) packaged, and b) deployed (courtesy of Wright [14]). 


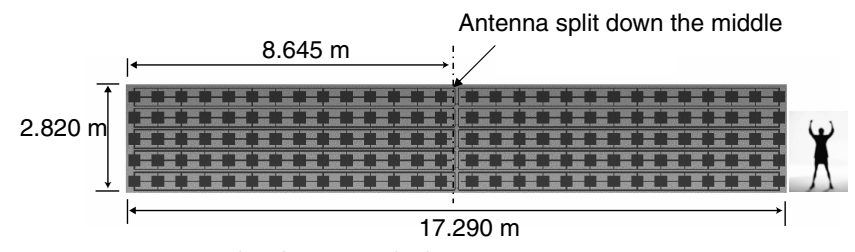

Fig. 4 Monolithic P-band antenna.
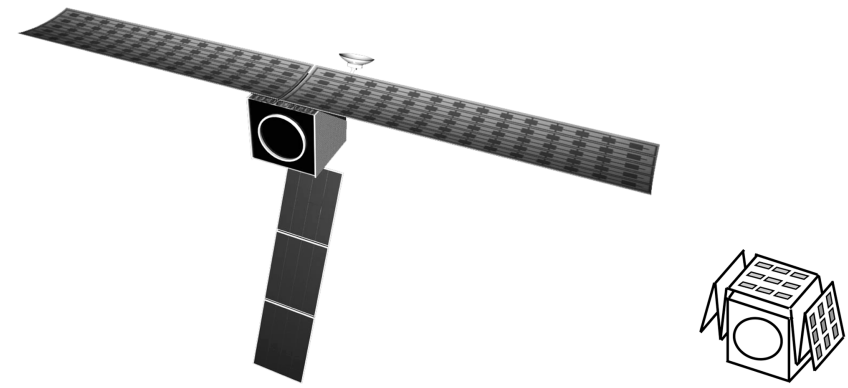

a)

b)

Fig. 5 Arrangement on spacecraft of monolithic array antenna: a) deployed, and b) folded.

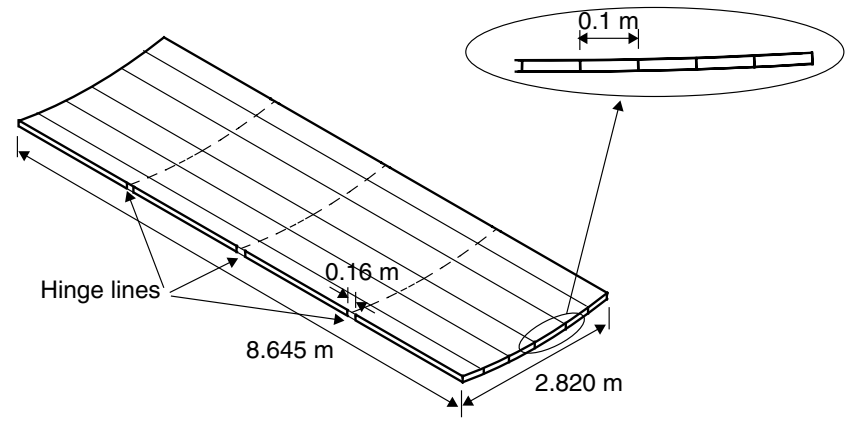

Fig. 6 FLATS concept (single wing).

cannot be folded, we will use a special kind of core that consists of longitudinal ribs only, without any transverse ribs.

Note that this structural concept provides a curved array rather than a planar array; however, a planar RF beam can be obtained by phase correction for the power source of each row. The transverse curvature of the array is not detrimental to the planarity specification, which, given the curved nature of the proposed solutions, really ought to be termed a surface accuracy requirement and not a planarity requirement.

Thus, the proposed structure consists of two curved cylindrical face sheets $20 \mathrm{~mm}$ apart, with internal unidirectional ribbing strengthening the longitudinal direction of the antenna. The structure can be folded at hinge lines where the internal ribs have been removed, whereas the face sheets bend to a compliant hinge similar to that seen in a steel tape measure. The structure is stress free when deployed and, hence, the stowing (flattening and folding) of the structure stores potential energy to create a self-deploying structure. The curved nature of the deployed structure allows it to lock into the desired shape on deployment.

This structural concept is ideally suited as a monolithic SAR; the front skin acts as the feed and radiating patches, whereas the rear skin acts as the ground plane. The nature of the structure allows continuous RF paths, even across the hinge lines. The radiating rows run in straight lines down the cylindrical shape. The material between the patches and the ground plane must be RF transparent and, hence, Kevlar has been chosen.

\section{B. Structural Analysis}

One wing of the deployed structure was analyzed using a finite element model consisting of thin shell elements, following an approach analogous to that presented in Yee and Pellegrino [11]. The analysis showed that, with a four-ply plain-weave Kevlar lay up for each skin and unidirectional ribs spaced approximately every $100 \mathrm{~mm}$, the deployed fundamental natural frequency of vibration was about $0.9 \mathrm{~Hz}$ (see Fig. 7a), which is above the $0.5 \mathrm{~Hz}$ minimum requirement and acceptably close to the $1 \mathrm{~Hz}$ goal. The model was constrained at four points, at the ends of the external support ribs that attach the antenna to the platform. An analysis of the thermal distortion due to a thermal gradient of $90^{\circ} \mathrm{C}$, for the antenna viewing toward the sun, gave a maximum normal displacement of $34 \mathrm{~mm}$ at the tip corners. In most of the antenna, the displacement is less than $20 \mathrm{~mm}$.

Throughout the analysis, the Kevlar composite was assumed to have an isotropic elastic modulus of $35.6 \mathrm{GPa}$ and a coefficient of thermal expansion of $2.35 \times 10^{-6 \circ} \mathrm{C}^{-1}$. The cured thickness of one ply is $0.075 \mathrm{~mm}$.

The predicted mass of the structure was $1 \mathrm{~kg} / \mathrm{m}^{2}$, whereas the load required to flatten one wing was predicted to be $160 \mathrm{~N}$ applied along the edges of the antenna. This results in stresses of only $12 \mathrm{MPa}$ (with $500 \mathrm{MPa}$ at a strain of $1.4 \%$ being the ultimate strength, $120 \mathrm{MPa}$ at a strain of $0.3 \%$ the tensile yield, and $60 \mathrm{MPa}$ at a strain of $0.2 \%$ the compressive yield).

For the antenna fully folded, the fundamental natural frequency of vibration of the stowed panels was predicted at $10 \mathrm{~Hz}$ and, assuming typical design accelerations of $20 \mathrm{~g}$, the maximum panel deflection is $50 \mathrm{~mm}$ if linear behavior is assumed. However, at this low frequency nonlinear effects would in fact be significant, and so the maximum displacement is expected to decrease to less than $10 \mathrm{~mm}$.

A detailed analysis of a test piece using a finer mesh was carried out with ABAQUS [12], concentrating on the hinge-line folding process. The process is in two steps: flattening and "Z" longitudinal folding. Flattening is simulated by fixing one longitudinal edge of the structure and pulling the other edge away from it. At this point the structure is not completely flat, but it is sufficiently flat for the next stage of the simulation, which involves longitudinal folding, to be conducted successfully. The strain levels after flattening are insignificant. The formation of a longitudinal fold involves contact between the two skins in the hinge-line region; frictionless hard contact with finite sliding is assumed. The simulation of longitudinal folding is in two stages. First, one part of the structure is rotated $180 \mathrm{deg}$, whereas the other end is not allowed to move. Second, the moving part is pushed down against the fixed part, to tighten the fold region and so package the structure more compactly.

Figures $8 \mathrm{a}-8 \mathrm{c}$ show the contour plots of the maximum in-plane principal strains during the first stage. The maximum strain is $0.74 \%$, and occurs in a region of the inner skin, just at the inner end of the ribs. Figure 9 shows a contour plot of the maximum in-plane principal strains for the tightly packaged structure, when the two parts of the structure are almost in contact. The maximum principal strain has increased to $0.94 \%$.

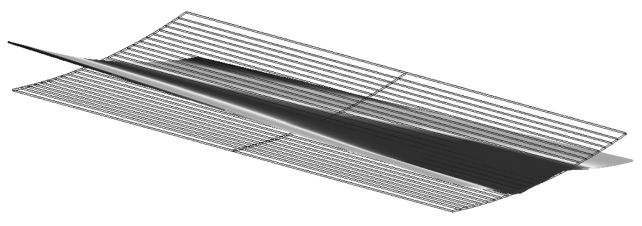

a)

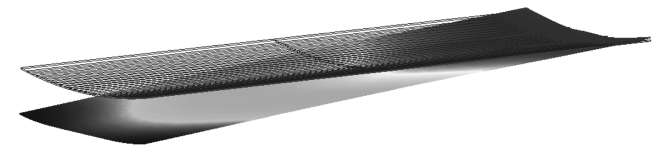

b)

Fig. 7 Natural modes of deployed half wing: a) twisting mode at $0.9 \mathrm{~Hz}$, and b) bending mode at $0.94 \mathrm{~Hz}$. 

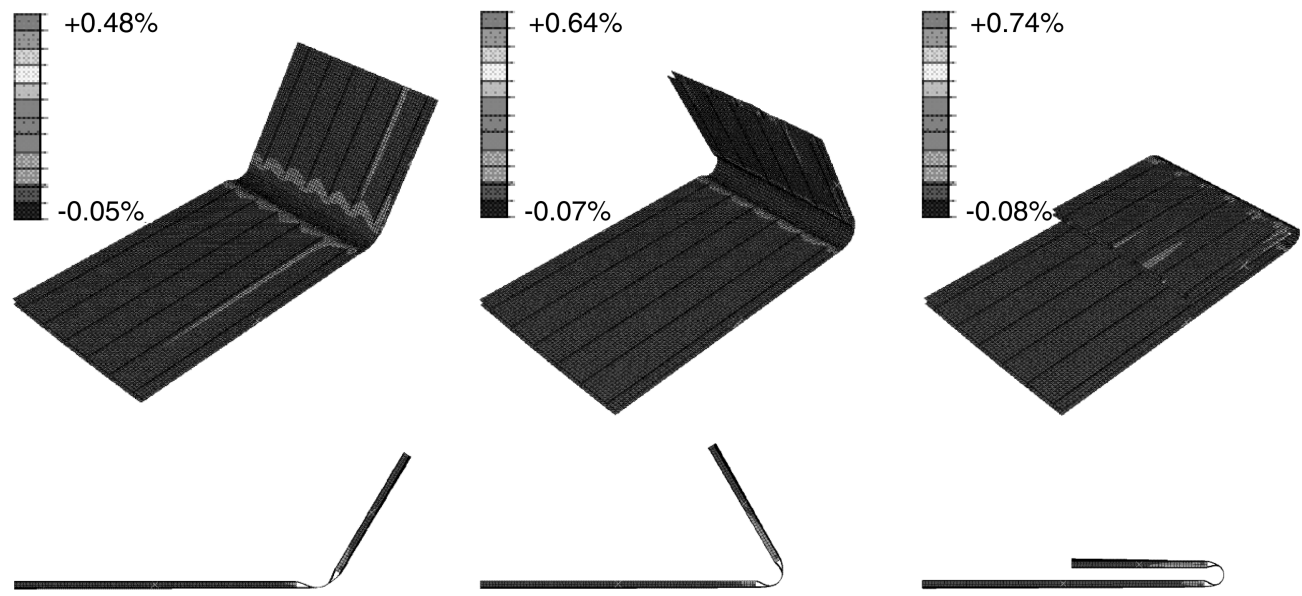

b)

c)

Fig. 8 Perspective and side views of folding simulation: a) $60 \mathrm{deg}$ folded, ) $120 \mathrm{deg}$ folded, and c) $180 \mathrm{deg}$ folded.

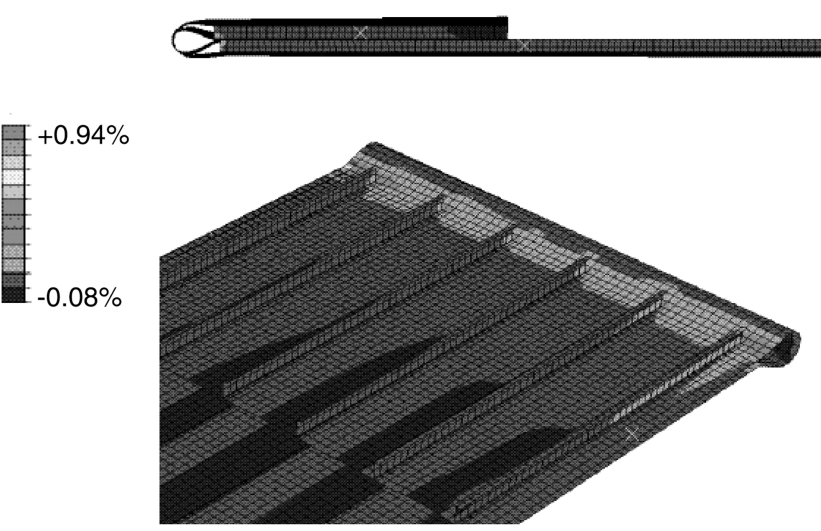

Fig. 9 Flattening process, bringing panels together.

\section{Manufacture}

\section{A. Test Pieces}

Two test pieces of one row each were manufactured, as shown in Figs. 10 and 11 .

In addition to these large test pieces, some sample hinge lines were made. Two hinge-line models were made from three- and four-ply lay ups, respectively. These models had different ply thicknesses to investigate which was best for the main test pieces. The four ply required more force to bend the hinge, thus creating more pressure on the internal ribs. The three-ply design is naturally less stiff, requiring less force to bend the hinge and, thus, applying less pressure to the internal ribs.

After bending the four-ply sample through 180 deg down to a radius of approximately $30 \mathrm{~mm}$ and then slowly releasing it until it became straight, the deformation of the material was not fully recovered (see Fig. 12). It was concluded that the Kevlar had been taken beyond its compressive yield limit. This was subsequently confirmed by an analysis of the stresses involved in the bending of a hinge, using the limiting values quoted in Sec. III.B. Hence, the maximum bending stresses in the skin were decreased by reducing the skin thickness to three plies and also limiting the bend radii, by means of spacers, to $40 \mathrm{~mm}$.

\section{B. Mold Tool}

The main test pieces require curved skins to produce the tapespring effect. Initially, a flat sheet of stainless steel under three-point bending was used as the mold tool, but this was later replaced with a four-point bending configuration using two tubes. The improved tool is shown in Fig. 13.

\section{First Test Piece}

The first test piece was manufactured on the initial mold tool and had only four internal ribs, to avoid them interfering with the RF connections. However, the unsupported span was too great, leading to poor control of the gap between the skins.

This structure has been folded and unfolded six times and Fig. 14 shows the hinge line when the structure is folded into its stowed state. Note that, whereas the curved structure flattens, the ribs do not.

The structural analysis described in Sec. III.B showed that the rigid panel sections on either side of the hinge line should not be brought into contact, otherwise the bend radii would be too tight and the skin material would deform permanently. Therefore, spacers were used to maintain the appropriate gap and bend radii. These spacers can be used as hard points to hold the stowed structure. An initial design with four cup and cone standoffs, with $50 \mathrm{~mm}$ diameter

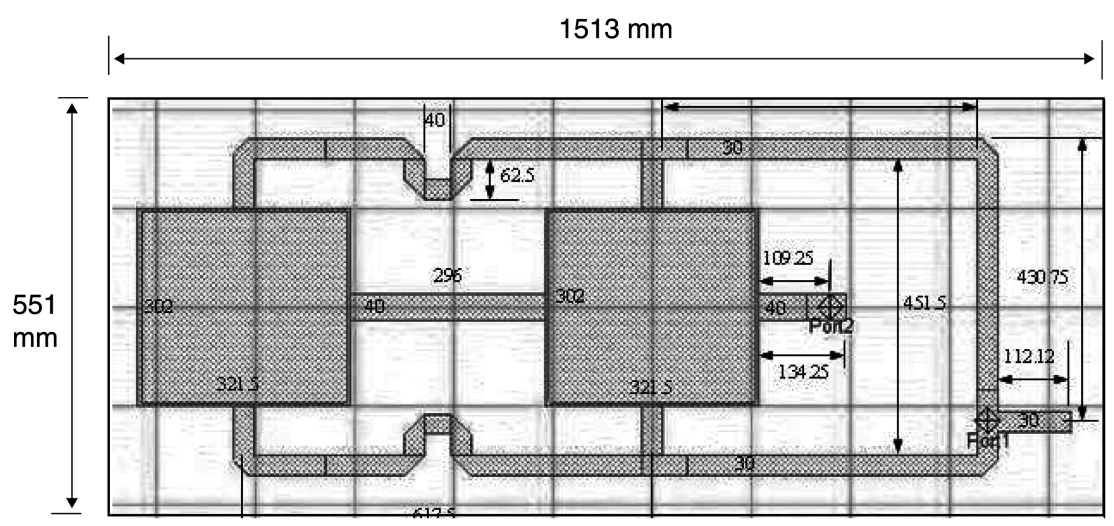

Fig. 10 Test piece. 

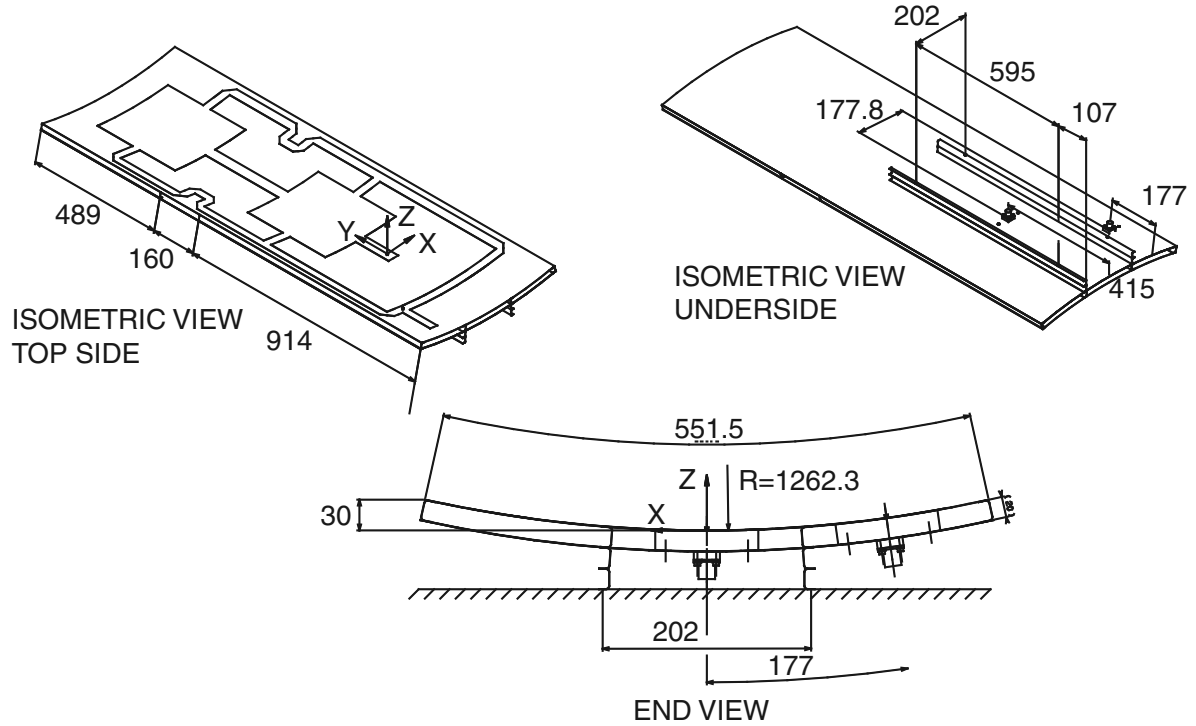

Fig. 11 Test-piece drawing, $\mathbf{m m}$.

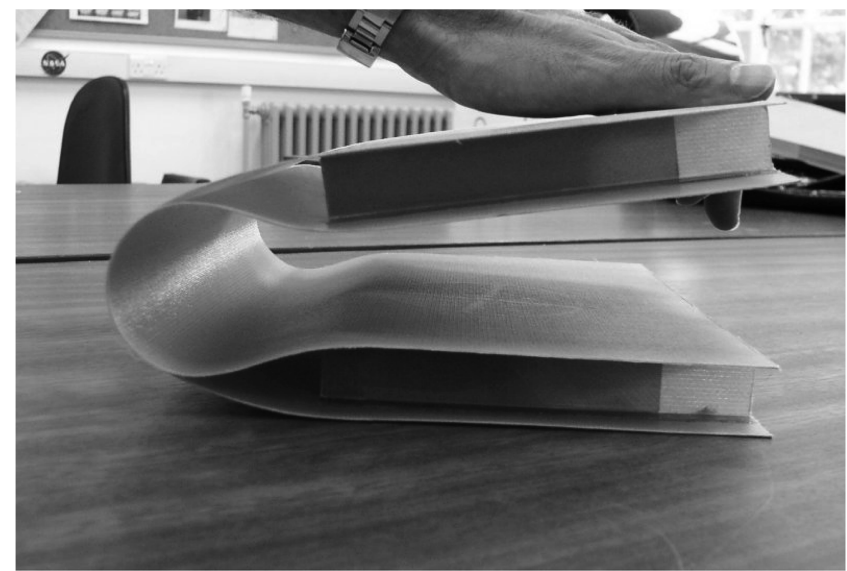

a)

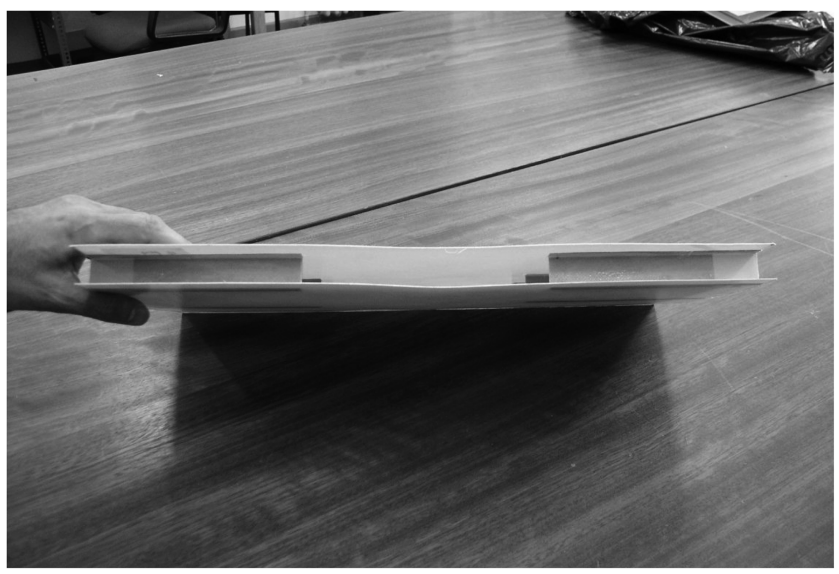

b)

Fig. 12 Hinge-line model with four-ply lay up showing residual deformation after bending.

and $40 \mathrm{~mm}$ height, was developed. This not only provides the required radii but also provides dynamic clearance for the launch loads.

This first structure was used in the assembly of the first test piece (see Fig. 15). This assembly was range tested for antenna pattern, gain, and cross-polar isolation. The antenna was then folded and unfolded and then retested.

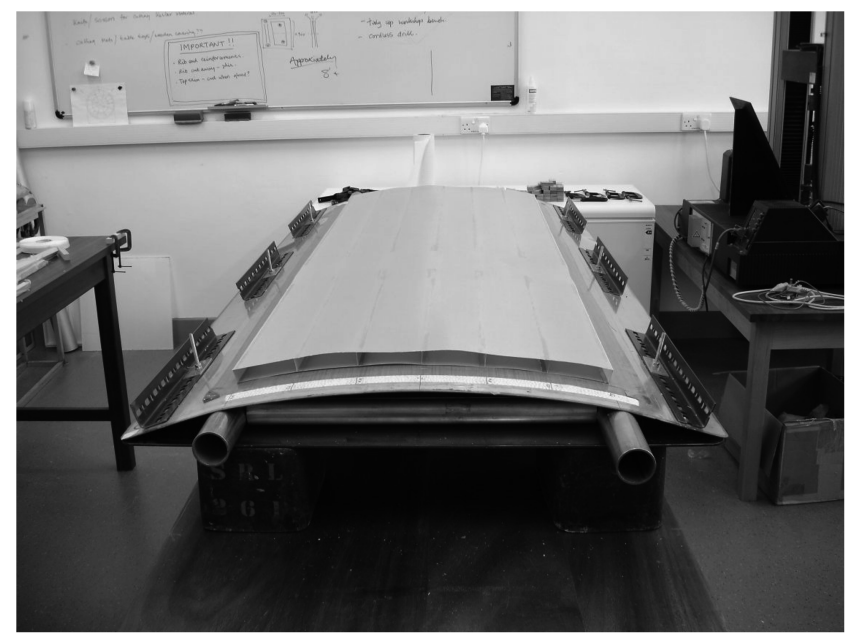

Fig. 13 Mold tool used for the second test piece.

\section{Second Test Piece}

A number of design improvements were made for the second structure:

1) The mold tool was improved by going to a four-point bending scheme.

2) The structure skins were reduced to three ply to avoid yield during bending of the hinges.

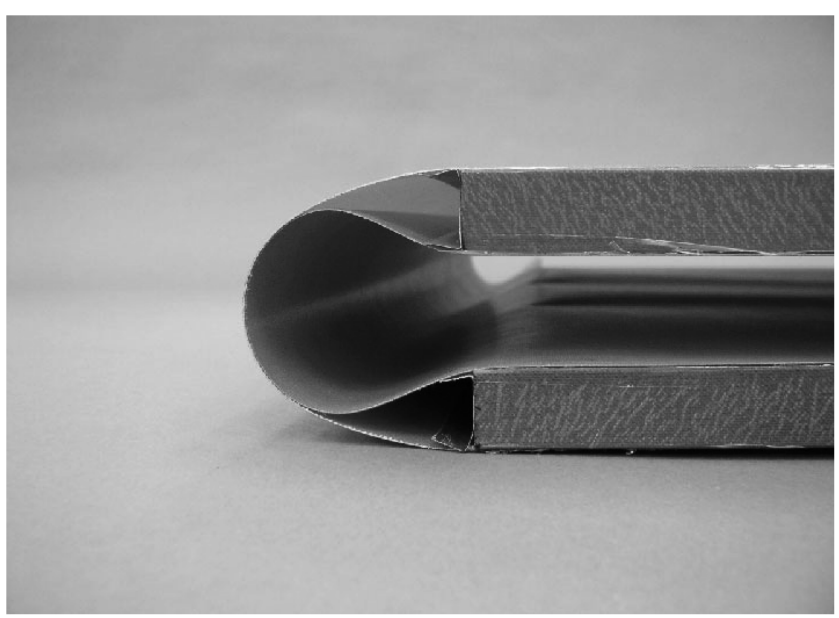

Fig. 14 Hinge line when antenna is stowed. 


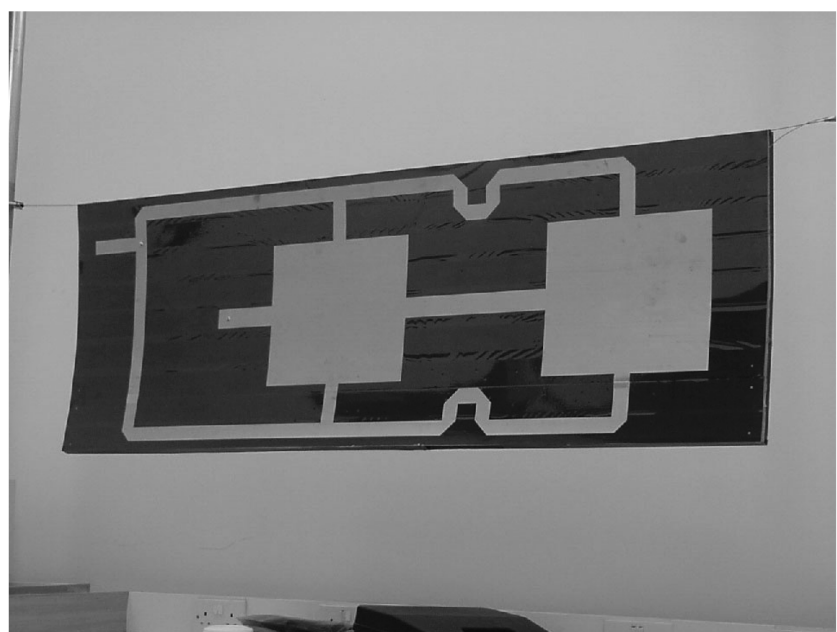

a)

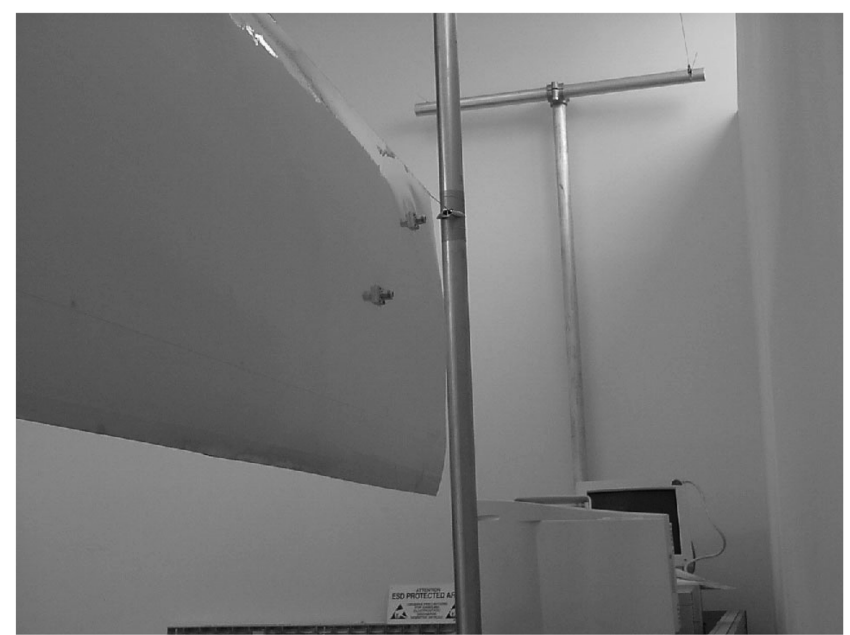

b)

Fig. 15 First test piece: a) hung for display, and b) showing connectors at the back.

3) The number of longitudinal ribs was increased from four to seven to provide improved gap control.

4) A $50 \mathrm{~mm}$ section of each rib either side of the hinge line was strengthened to prevent the buckling of these ribs during the folding process.

The resulting second structure shown in Fig. 16 was far superior to the first structure in that it maintained its curvature better and held the $20 \mathrm{~mm}$ gap between the skins more accurately. In fact, $95 \%$ of the

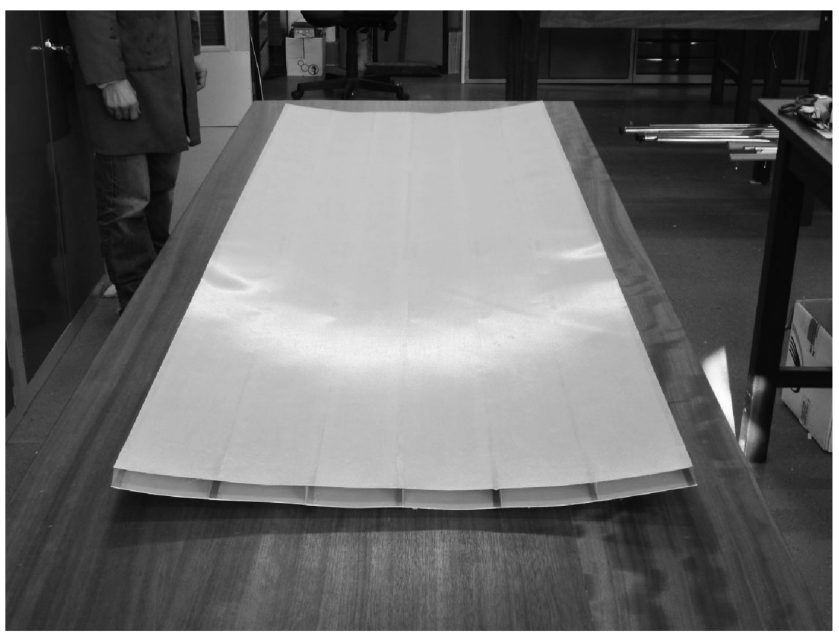

Fig. 16 Completed second structure.

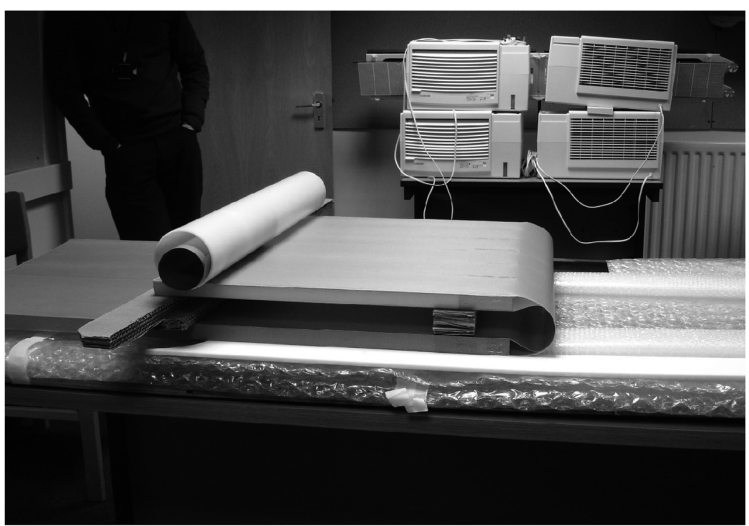

a) structure was well within specification for this size of test piece $( \pm 1 \mathrm{~mm})$. The only area out of tolerance was the free edges (extreme ends and edges of the hinge line).

The second structure has been folded and unfolded five times (see Fig. 17) in both directions. The changes that had been introduced in this test piece, namely the three-ply skins, ensuring that the bend radii remain greater than $40 \mathrm{~mm}$ by the use of spacers, the increase in internal ribs, and the stiffening of the ribs around the hinge line, meant that the folding process was far more robust than that of the first structure. Furthermore, no permanent distortion was found after folding.

\section{E. RF Feed and Radiating Patches}

The RF feed and radiating patches were manufactured by Printech using an etching process. The base material is copper-coated polyimide film from Sheldahl. The film consists of $50 \mu \mathrm{m}$ of polyimide (e.g., Kapton) coated on both sides with $5 \mu \mathrm{m}$ of copper. The circuit was attached to the structure using double-sided sticky tape; however, for a flight programme, this product could be cocured onto the Kevlar skin.

\section{Testing}

The first test piece was RF tested. Initially, the test piece was "bench" tested for input return losses and isolation between ports. The assembly was folded and unfolded, and then retested. No significant change in RF performance was seen.

The test piece was then mounted in an antenna range for further $\mathrm{RF}$ testing (antenna pattern, gain, and cross-polar isolation

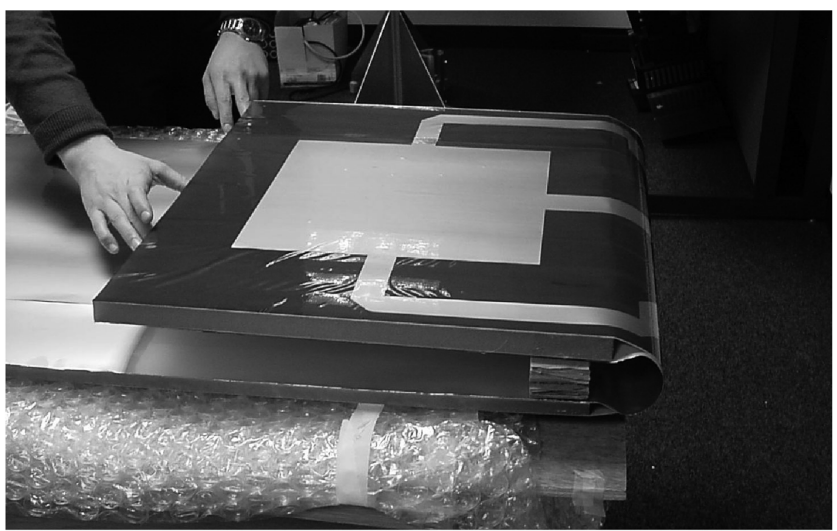

b)

Fig. 17 Folding of second test piece: a) 180 deg inwards, and b) 180 deg outwards. 


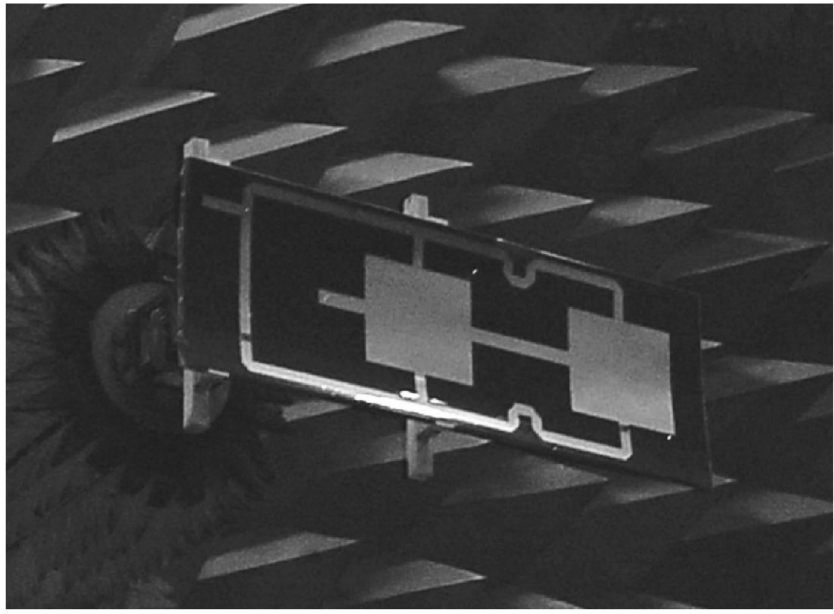

a)

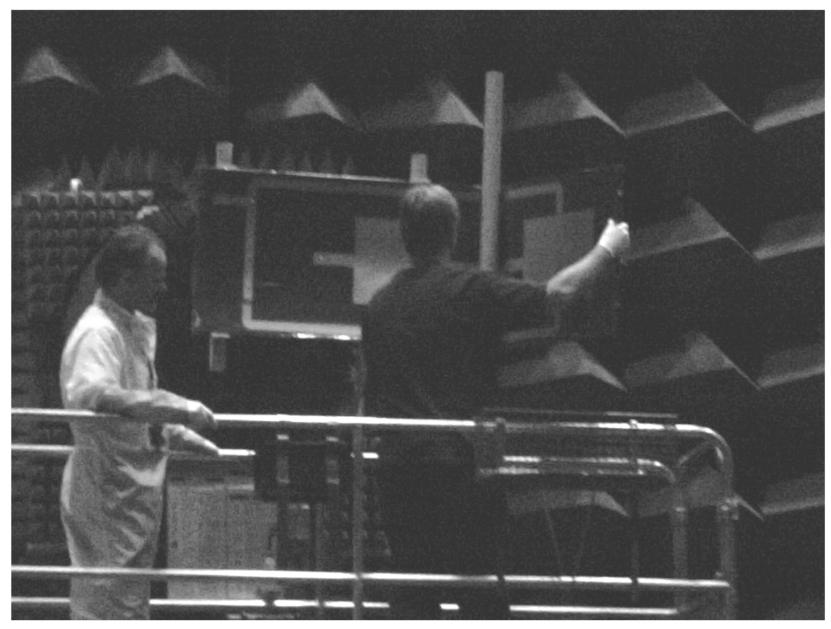

b)

Fig. 18 a) antenna range testing of first test piece, and b) test piece being folded.
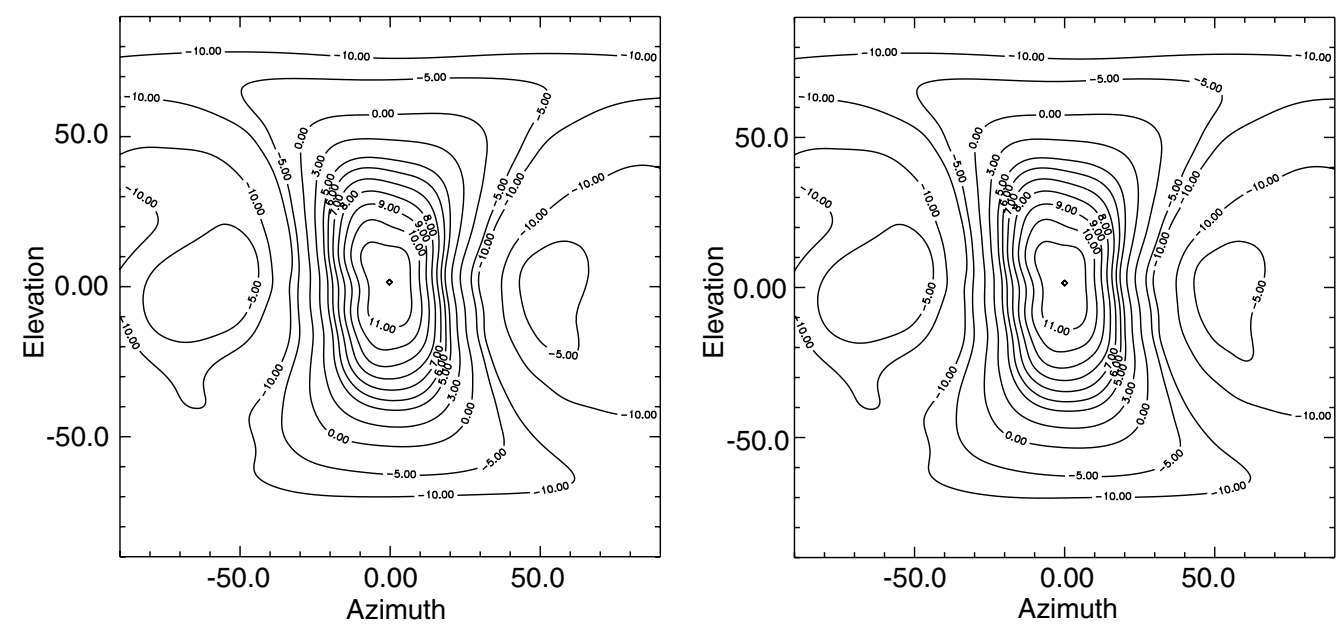

Fig. 19 Typical results from the first test piece: a) prefold pattern: directivity $=12.61 \mathrm{~dB} \mathrm{i}$, gain $=11.89 \mathrm{~dB} \mathrm{i} \pm 0.25 \mathrm{~dB}$ (error); and b) postfold pattern: directivity $=12.63 \mathrm{~dB} \mathrm{i}$, gain $=11.95 \mathrm{~dB} \mathrm{i} \pm 0.25 \mathrm{~dB}$ (error).

measurements) (see Fig. 18). Again, the antenna was folded, unfolded, and retested. The RF performance did not change. Examples of typical results are presented in Fig. 19 and show good correlation between measurements of beam profile before and after deployment.

\section{Discussion}

The design concept of this antenna structure is based on the shape and properties of a tape spring. The key structural advantage of the FLATS concept is that it is able to provide the required stiffness and structural stability in the deployed configuration, while also being flexible enough that the structure can be folded without damage or change in its RF performance. The design feature that makes it possible to achieve this is the use of unidirectional ribs that are interrupted at the hinge lines. A general design approach for achieving this kind of behavior has been presented in Tan and Pellegrino [13].

Future mechanical work should look at the choices of material, particularly the rear face sheet that does not need to be RF transparent if the metallized layer is on the top. Also, a deployment scheme will need to be selected and demonstrated.

\section{Conclusions}

A monolithic array using a FLATS structure has been identified as the design with the highest potential for large low-frequency antennas. The overall antenna design has 5 rows with 28 elements per row, covering an area of 2.82 by $17.29 \mathrm{~m}$ (approximately $50 \mathrm{~m}^{2}$ ), split into two equal wings of 5 rows by 14 elements. The continuity of the proposed monolithic antenna design is a very desirable feature, as it avoids the complexity and expense of providing RF transmission across the gap of a more traditional hinge.

The design uses a curved FLATS structure, which follows the basic principle of a tape spring that can be folded flat and $\mathrm{Z}$ folded, yet it springs back to its original, undamaged shape on release. The energy required to fold the structure is stored as elastic strain energy in the structure and is used as the deployment energy. A deployment control system has yet to be designed.

Test pieces have been made to demonstrate both the RF and mechanical aspects of the design, particularly the RF performance before and after folding the structure.

This study has investigated different technologies that might be considered for use in a large, low-frequency SAR antenna. The potential for a low-mass, low-cost, simple, and reliable design offered by the FLATS design was recognized in the tradeoff study. The design itself has been investigated both analytically and via test pieces and has been shown to be a viable solution to the problems posed by such large antennas.

\section{Acknowledgments}

The work presented in this paper was part of an ESA-funded study of antenna technologies for operation at low frequencies (contract no. 18120/04/NL/FM under GSTP, Project Manager Peter Rinous). 
The project team was led by EADS Astrium (Project Manager David Hall) and included BAE Systems ATC, the Centre for Terrestrial Carbon Dynamics at Sheffield University, and the Deployable Structures Laboratory at the University of Cambridge.

\section{References}

[1] Wofsy, S. C., "Where Has All the Carbon Gone?," Science, Vol. 292 2001, pp. 2261-2263. doi:10.1126/science. 1061077

[2] Fang, J., Chen, A., Peng, C., Zhao, S., and Ci, L., "Changes in Forest Biomass Carbon Storage in China Between 1949 and 1998," Science, Vol. 292, 2001, pp. 2320-2322. doi:10.1126/science.1058629

[3] Imhoff, M. L., "A Theoretical Analysis of the Effect of Forest Structure on Synthetic Aperture Radar Backscatter and the Remote Sensing of Biomass," IEEE Transactions on Geoscience and Remote Sensing, Vol. 33, No. 2, 1995, pp. 341-352. doi: $10.1109 / 36.377934$

[4] Quegan, S., Le Toan, T., YU, J. J., Ribbes, F., and Floury, N., "Multitemporal ERS SAR Analysis Applied to Forest Mapping," IEEE Transactions on Geoscience and Remote Sensing, Vol. 38, No. 2, 2000, pp. 741-753. doi: $10.1109 / 36.842003$

[5] Wuest, W., "Einige Anwendungen der Theorie der Zylinderschale," Zeitschrift fuer Angewandte Mathematik und Mechanik, Vol. 34, 1954, pp. 444-454. doi:10.1002/zamm.19540341203

[6] Rimrott, F. P. J., "Storable Tubular Extendible Member: A Unique
Machine Element," Machine Design, Vol. 37, No. 28, Dec. 1965, pp. 156-163.

[7] Calladine, C. R., "The Theory of Thin Shell Structures 1888-1988," Proceedings of the Institution of Mechanical Engineers Part A, Journal of Power Engineering, Vol. 202, 1988, pp. 1-9.

[8] Seffen, K. A., and Pellegrino, S., "Deployment Dynamics of Tape Springs," Proceedings of the Royal Society of London, Series A Mathematical and Physical Sciences, Vol. 455, 1999, pp. 1003-1048. doi:10.1098/rspa.1999.0347

[9] Yee, J. C. H., Soykasap, O., and Pellegrino, S., "Carbon Fibre Reinforced Plastic Tape Springs," AIAA Paper 2004-1819.

[10] Mobrem, M., and Adams, D. S., "Analysis of the Lenticular Jointed MARSIS Antenna Deployment," AIAA Paper 2006-1683.

[11] Yee, J. C. H., and Pellegrino, S., "Composite Tube Hinges," Journal of Aerospace Engineering, Vol. 18, Oct. 2005, pp. 224-231. doi:10.1061/(ASCE)0893-1321(2005)18:4(224)

[12] AB AQUS/Standard User's Manual, Ver. 6.4., Hibbitt, Karlsson \& Sorensen, Inc., Pawtucket, RI, 2004.

[13] Tan, L. T., and Pellegrino, S., "Thin-Shell Deployable Reflectors with Collapsible Stiffeners: Part 1 Approach," AIAA Journal, Vol. 44, No. 11, 2006, pp. 2515-2523.

[14] Wright, D., "Design, Integration and Testing of an Advanced Synthetic Aperture Radar," IUTAM-IASS Symposium on Deployable Structures: Theory and Applications, edited by S. Pellegrino, and S. D. Guest, Kluwer, Dordrecht, The Netherlands, 2000, pp. 467-476.

G. Agnes Associate Editor 